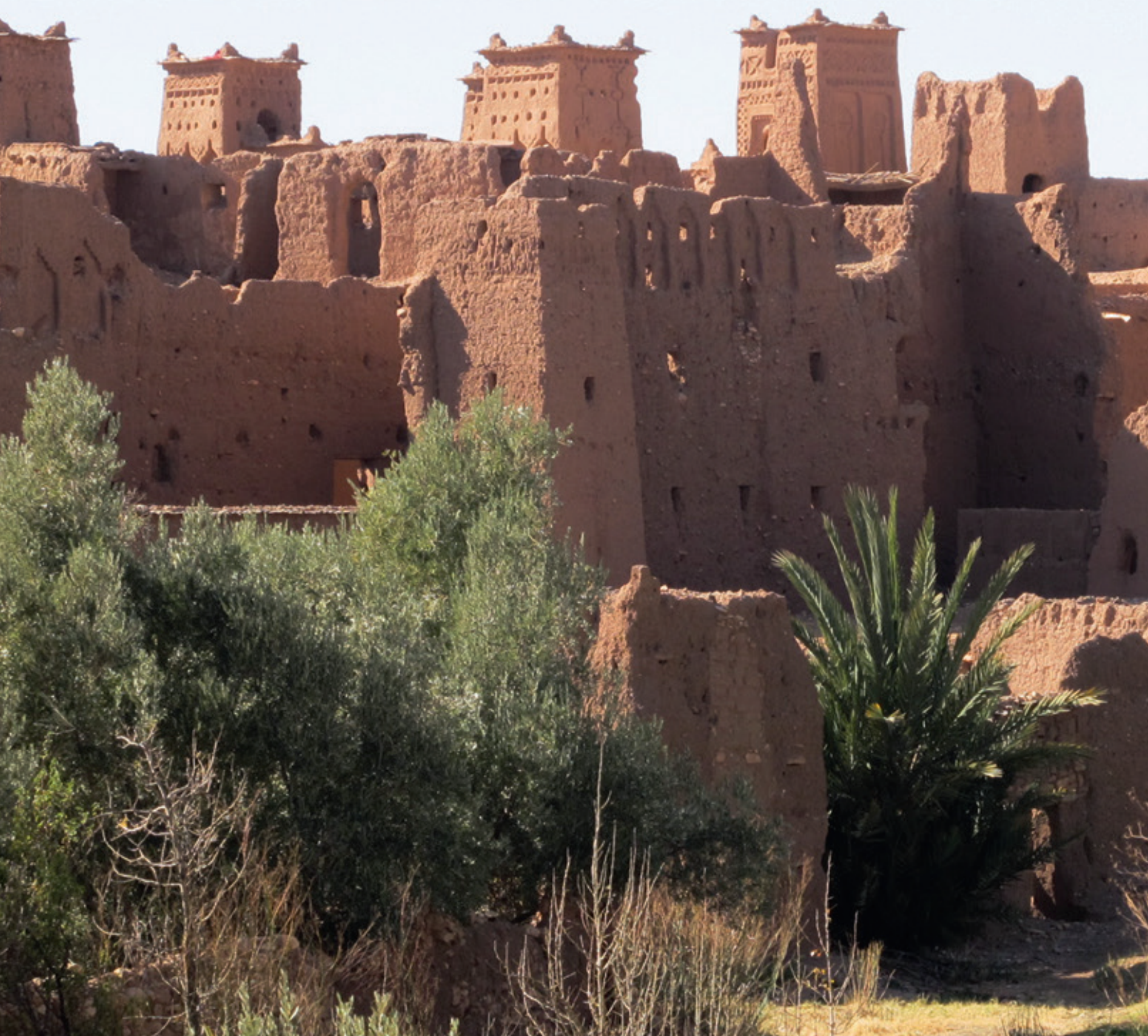
1. Hen 


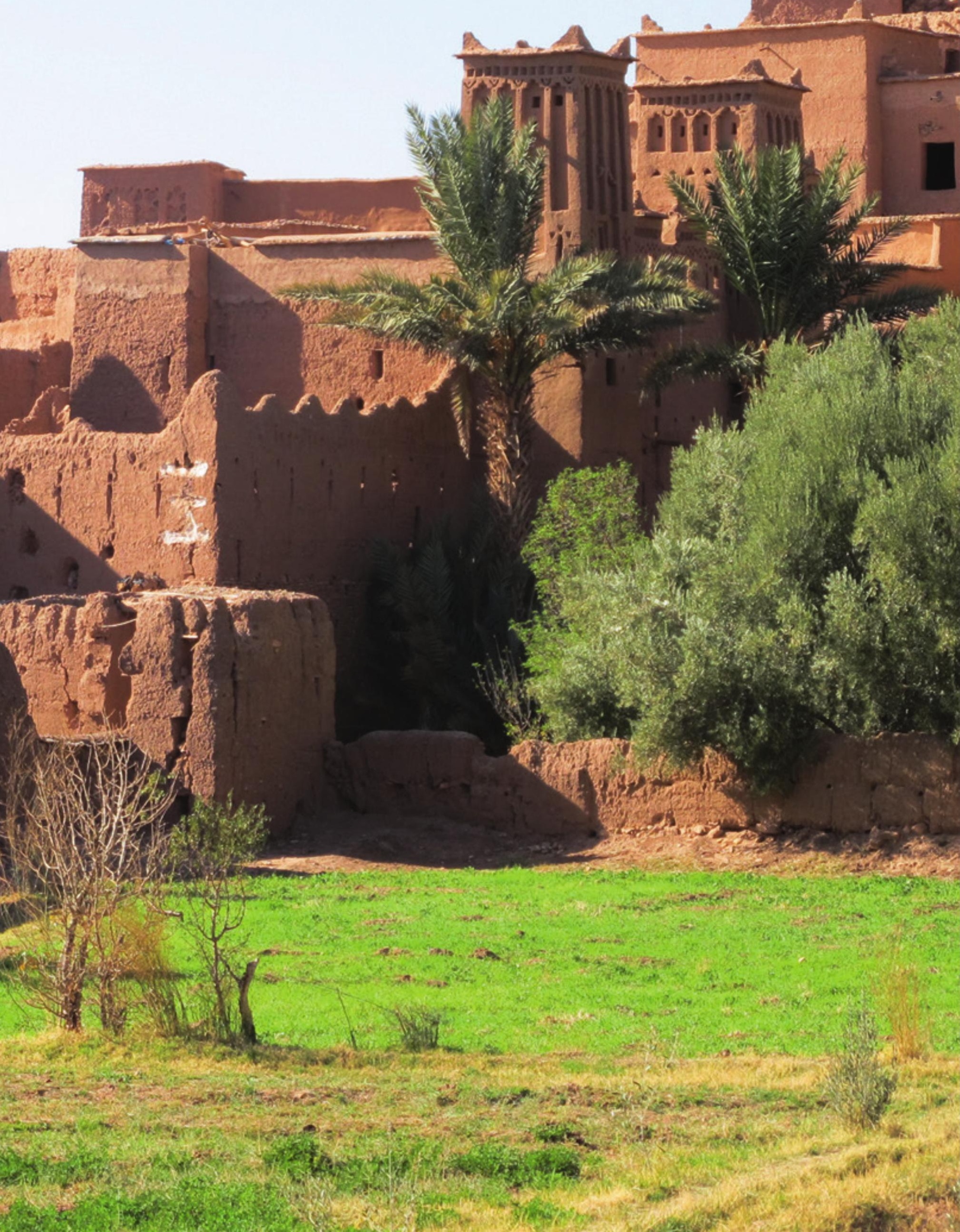




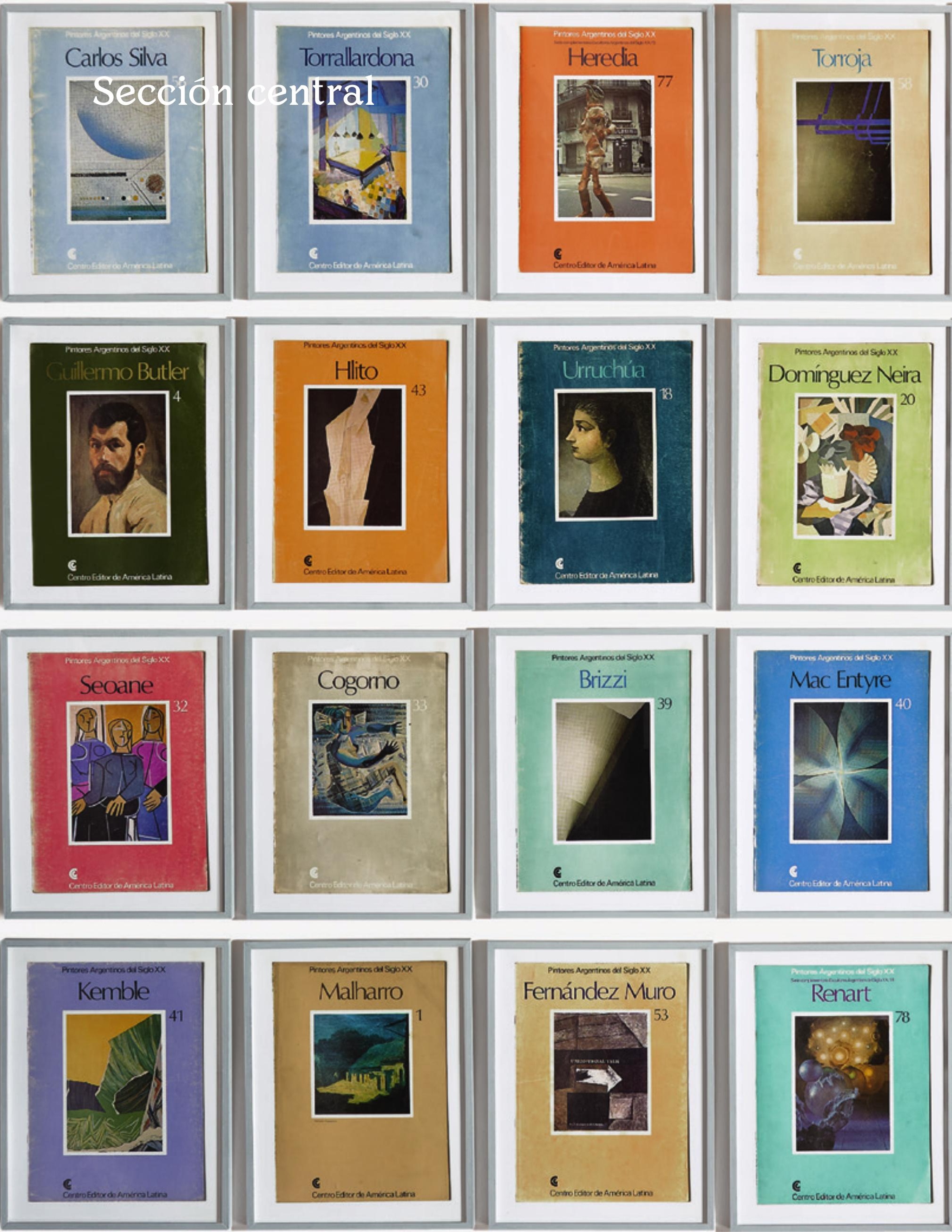




\section{La Historia del Arte como libro: definiciones y crisis de un espacio de inscripción ${ }^{1}$}

\section{Artículo de investigación}

Recibido: 5 de agosto de 2017

Aprobado: 22 de septiembre de 2017

\section{Juan Cruz Pedroni}

Universidad Nacional de La Plata, Argentina

pedronijuancruz@gmail.com

Cómo citar este artículo: Pedroni, Juan Cruz (2018). La Historia del Arte como libro: definiciones y crisis de un espacio de inscripción. Estudios Artísticos: revista de investigación creadora, 4 (4) pp.16-29. DOI: https://doi.org/10.14483/25009311.12930

El presente trabajo se inscribe en una investigación realizada con una beca tipo A otorgada por la Universidad Nacional de La Plata (Instituto de Historia del Arte Argentino y Americano, Facultad de Bellas Artes), dirigida por la Dra. Berenice Gustavino y el Lic. Rubén Hitz Guillermo Faivovich, (2011) Pinturas y fotografías.

\section{Resumen}

Como artefacto escrito y visual, el objeto libro tiene un lugar central en la inscripción histórica de la obra de arte. Algunas prácticas artísticas contemporáneas comentan esta centralidad e interpelan el discurso histórico-artístico a través de un uso poético de sus soportes impresos. En el presente trabajo proponemos, en primer lugar, un acercamiento teórico a la disciplina Historia del Arte a través de sus despliegues materiales en el libro, considerada como un dispositivo y un espacio de inscripción que promueve determinados efectos de sentido. A partir de estos aportes teóricos, reflexionamos, en un segundo momento, sobre una serie de prácticas de artistas argentinos en las que el discurso de la Historia del Arte y sus soportes impresos aparecen tematizados. Estas prácticas son interpretadas como síntomas de una crisis de determinadas creencias en torno a la Historia y al libro como espacios de inscripción de lo artístico.

Palabras clave

Arte contemporáneo, cultura del libro, dispositivo, historiografía del arte.

\section{The History of Art as a Book: Definitions and Crisis of an Inscription Space}

\footnotetext{
Abstract

As a written and visual artifact, the artist's book have a central place in the historical inscription of the work of art. Some contemporary artistic practices comment on this centrality and question the historical-artistic discourse through a poetic use of its printed supports. In the present paper we propose, first, a theoretical approach to the discipline of History of Art through its material displays in the
} 
book, considered as a device and an inscription space that promotes certain effects of meaning. From these theoretical contributions we reflect, then, on a series of practices of Argentine artists in which the discourse of the History of Art and its printed supports appear as a main theme. These practices are interpreted as symptoms of a crisis of certain beliefs about History and the book as spaces for inscription of the artistic.

\section{Keywords}

Contemporary art, book culture, device, art historiography.

\section{L'histoire de l'art en tant que livre : définitions et crise d'un espace d'inscription}

\section{Résumé}

En tant qu'objet écrit et visuel, le livre-objet occupe une place centrale dans l'inscription historique de l'œuvre d'art. Certaines pratiques artistiques contemporaines commentent cette centralité et interpellent le discours historico-artistique à travers une utilisation poétique de ses supports imprimés. Dans le présent travail, nous proposons, en premier lieu, une approche théorique de la discipline de I'histoire de l'art à travers ses expositions matérielles dans le livre, considéré comme un dispositif et un espace d'inscription qui favorise certains effets de sens. À partir de ces contributions théoriques, nous réfléchissons, dans un second moment, à une série de pratiques d'artistes argentins dans lesquelles le discours de l'histoire de l'art et de ses supports imprimés apparaît sur le thème. Ces pratiques sont interprétées comme des symptômes d'une crise de certaines croyances sur l'histoire et le livre comme des espaces d'inscription de l'artistique.

\section{Mots clés}

Art contemporain, culture du livre, dispositif, historiographie de l'art.

\section{A História da Arte como livro: definições e crise de um espaço de inscrição}

\section{Resumo}

Como artefato escrito e visual, o objeto livro tem um lugar central na inscrição histórica da obra de arte. Algumas práticas artísticas contemporâneas comentam esta centralidade e interpelam o discurso histórico-artístico através de um uso poético de seus suportes impressos. No presente trabalho propomos, em primeiro lugar, uma abordagem teórica da disciplina História da Arte através dos materiais exibidos no livro, considerado como um dispositivo e um espaço de inscrição que promove determinados efeitos de sentido. A partir destes aportes teóricos, refletimos, em um segundo momento, sobre uma série de práticas de artistas argentinos nas quais o discurso da História da Arte e seus suportes impressos aparecem tematizados. Estas práticas são interpretadas como sintomas de uma crise de determinadas crenças em torno da História e do livro como espaços de inscrição do artístico.

\section{Palavras-chave}

Arte contemporânea, cultura do livro, dispositivo, historiografia da arte.

\section{Panga kilkaska parlukunamanda: Mana pudiringasinapi sug iuashpi kaskapi}

\section{Maillallachiska}

Kilkaska i kawaspa sug artefactokuna, chi kilkaska iukami sug iuarh chagpipi sug suti parlu ruraskamanda. Maikankuna ruraikuamanda sugpunchakuna ninkuna kai chagpi rimaikunamanda parlu sug ruraikunamanda rimai imasa tiaskamanda. Kai ruraikunamanda ninchimi, kaiaia kai ruraskamanda kilkaspa iura pangakunapi, maipi kawaskasinapi sug tiaskapi chi luarch sutimanda chasa kai andami suma iuiaringapa. Kai aidaikunakunawa, iuirinchimi iskai iuiariipi, kai kami sug maishukuna suraska kai suti Argentinamanda kaskakuna. Chi parlukanamanda kaska i chasa ruraskakuna kawarinmi tiaska. Kai ruraikuna kawarimi mana suma allí ruraskakuna ima iachachiskasina antiwawamandakuna i iura pangapi kilkaska sug iuarkunapi ruraskakuna.

\section{Rimangapa Ministidukuna}

Kunaura ruraskamanda iura panga antiwamanda iachachiskakuna, tiaska, antiwamanda iachachiskakuna. 


\section{Introducción}

El presente trabajo pretende contribuir a una caracterización teórica de la Historia del Arte como dispositivo y como espacio de inscripción, a partir de consideraciones de Jacques Derrida sobre el libro y la escritura y de la línea francesa en la reflexión sobre el concepto de dispositivo. Enfocamos el problema a través de una reflexión sobre el libro como artefacto material complejo, entendiendo que el modo material de inscripción de un texto, su puesta en un objeto impreso en el que entra en relación de contigüidad física con imágenes, tiene un lugar central en la producción de sentido. Consideramos que este postulado metodológico sobre la materialidad de los discursos tiene una relevancia particular para el estudio crítico de una disciplina como la Historia del Arte que funda sus figuras del saber en la visualidad.

En segundo lugar, se estudian algunos proyectos artísticos contemporáneos que podemos describir como operaciones de lectura sobre la historiografía del arte tradicional. ${ }^{1}$ La hipótesis en la que se apoya este segundo momento de la investigación sostiene que estas prácticas ponen en crisis el dispositivo histórico-artístico tal como lo caracterizaremos, al tematizar y visibilizar algunos de sus mecanismos. Esta provocación de los artistas al dispositivo de la Historia del Arte a través de prácticas con fuertes rasgos metadiscursivos, no discuten sobre una manera de hacer arte $^{2}$ sino que responden a una manera con la cual la historiografía produce el espacio mismo de lo artístico. En estas prácticas, el recurso al libro de Historia del Arte como material poético revela la historicidad de una forma institucionalizada de constitución de la obra de arte.

La escritura de la historia del arte es una operación que produce un lugar para la obra de arte, a la

\footnotetext{
1 El concepto veroniano de operación de lectura u operación de reconocimiento fue utilizado en el ámbito de una reflexión estética por Federico Baeza (2010) en su estudio de prácticas artísticas que ingresan experiencias sensibles del mundo cotidiano al archivo cultural de las artes.

2 Este último tipo de conversación agonística entre el presente y el pasado es el que rige el arte de la modernidad e incluso el del posmodernismo considerado como un estilo histórico. Como veremos, en las prácticas que consideramos se trata de otro escenario de discusión.
}

que localiza en las coordenadas de un saber y de un sistema social de los objetos. En este sentido, lo que ninguna Historia del Arte puede dejar de escribir es el estatuto artístico de sus objetos. Esta tesis de existencia es el límite más allá del cual la historia del arte dejaría de existir como institución discursiva.

Desde la perspectiva que aquí intentaremos argumentar, el carácter artístico de un objeto queda definido por los lugares en los que ha sido escrito. La historia del carácter artístico de un objeto corresponde a su historia archivística, entendiendo por archivo "lo ya dicho al nivel de su existencia" según la formulación enunciada por Michel Foucault en su Arqueología y recuperada en Arte y archivo por Anna María Guasch (2010, p. 48). El movimiento por el cual la Historia del Arte se erige como arconte de ese archivo, vale decir, como autoridad que regula su interpretación a través de técnicas específicas (Derrida, 1997) es también un movimiento de confirmación de la obra de arte como tal, en otras palabras, el movimiento de su asignación a la categoría de obra.

La historiografía el arte más conservadora ha sostenido sobre sí misma una ficción de transparencia que podemos caracterizar de fonologocéntrica. La obra de arte pasa por ser un origen que la escritura de la historia solo viene a confirmar, un momento de sentido pleno en sí mismo frente al cual la historiografía se limitaría a reconocer el sitio que le estuvo destinado desde su origen. La escritura registra algo que ya existiría plenamente en otra parte. Respecto a la Historia del Arte, la obra tendría una evidente anterioridad y sería la fuente de una verdad que la escritura de la historia solamente recogería.

Una metonimia de uso corriente, sin embargo, consiste en decir que un artista escribió una página en la historia o que su obra comporta un capítulo de la Historia del Arte. En esta figura aparece reflejada la tesis denegada y contraria a la opinión más extendida, aquella que afirma que el espacio de inscripción antecede al acto de creación. Con el surgimiento de las historias del arte la dispersión de las imágenes es conjurada mediante la invención de un espacio que representa su reunión. Este espacio es el del libro, en el que las imágenes se reinscriben a través de la écfrasis y 
la reproducción, y de la asignación a un marco gráfico y material, en el que éstas aparecen como obras.

La Historia del Arte es el modo de inteligibilidad de lo que llamamos arte (Rancière, 2005) en cuanto permite poner en suspenso las diferencias que existen entre sus objetos mediante una identidad que solamente opera dentro de sus dominios. ${ }^{3} \mathrm{La}$ figura de esa historia es la de un cuerpo organizado de estilos históricos y de artistas que reproducen en su obra, como en un juego de cajas chinas, la misma segmentación por períodos que rige todo el proceso. Cada artista es creador de un cuerpo de objetos repartidos en etapas sucesivas y excluyentes entre sí, cuya unidad restituye y asegura la firma, signatura del origen que se inscribe en cada obra. En el plano retórico, las metáforas biológicas (Renacimiento, florecimiento, decadencia) confirman el carácter de corpus orgánico de este cuerpo de obras. La Historia del Arte escribe las entidades y los eventos a través de esta gramática de producción con la que unos sujetos y unos objetos quedan conservados dentro de contornos inalterables, movidos por reglas que prescriben la relación entre determinados conjuntos y la interdicen entre otros. George Didi-Huberman, caracterizó el discurso de la Historia del Arte por su tono, como una retórica de la certeza (2010). Ese afán de certidumbres deja sus marcas en la transparencia de un discurso en el que los instrumentos de pensamiento no tienen opacidad y en el que el pasado aparece como una serie de datos evidentes por sí mismos. Se trata de un efecto de certeza que esconde las atribuciones de subjetividad y de objetividad a una realidad de la que se quitan el devenir y lo impersonal. Los sujetos y objetos con los que este saber se piensa se encuentran a menudo sustancializados, con el resultado de que todo lo que circula por debajo del umbral que estas categorías instalan, permanece imperceptible o es atribuido a la voluntad de un artista o los valores de una obra. Podemos afirmar de este modo, con una expresión de Deleuze y

3 Una enumeración de R. Debray, es elocuente sobre la perpleiidad que suscita esta reunión de heterogéneos bajo el nombre del arte: "¿En nombre de qué se pueden poner entidades tan heterogéneas como las Venus esteatopigias de la Prehistoria, Atenea Parthenos, la Virgen del donante, La dama de Auxerre y las señoritas de Aviñón bajo un factor común?" (1994, p. 129).
Guattari, que se fabrica "un buen Dios para explicar movimientos geológicos" (2004, p. 9).

En el mismo aumento de lo disponible que configura el ámbito libresco, se producen efectos de sentido imprevisibles en la distribución que esas imágenes tenían previamente, antes de que se fabrique con ellas un corpus. De este modo, el espacio de la historia se escribe como un remedio contra la ausencia de las imágenes y en este mismo movimiento, se inviste a sí mismo con el efecto de una presencia que aparenta haber estado desde siempre. Esa presencia es la de un cuerpo de obras que solo existe a partir de la escritura, un corpus que solo empieza con el pasaje de las imágenes al emplazamiento del libro.

Desde los aportes teóricos de Jacques Derrida, conocemos esta lógica como economía del suplemento. La escritura de la historia que se pretende como un espacio de conservación de lo idéntico no deja de dispersar, sin embargo, el sentido de lo que inscribe. Como signo de un signo, la historia del arte representa a la obra de arte; es su suplente -actúa en su ausencia- pero con esta suplencia no se limita a ocupar un lugar que ya existía sino que produce la posición en que se constituye como obra. Como complemento o prótesis de nuestra memoria, nos permite acceder a imágenes a las que no tendríamos acceso de otra forma; pero este ingreso de la obra al archivo es siempre "un sistema de encuadre a la vez impuesto y borrado" (Derrida, 2010, p. 79), producción de un signo que oculta su dispositivo de inscripción. La Historia del Arte es un suplemento, un complemento que usurpa el lugar de esa obra cuya ausencia viene a cubrir a través de la reproducción y de las técnicas de escritura que le son más peculiares: la écfrasis y la serialización.

Con la inscripción de la obra de arte en el régimen de la historia son desactivadas algunas conexiones entre la configuración objetivada como obra de arte y el mundo en el que surge, que responden al devenir y a la vida como principio impersonal. ${ }^{4}$ En el mismo movimiento, otros encadenamientos son confirmados en su sitio y postulados como necesarios. Estos últimos, son aquellos que respon-

\footnotetext{
4 Estos tópicos de la filosofía de Gilles Deleuze aparecen expuestos en forma sintética en Beaulieu, A. (2012). Cuerpo y acontecimiento. La estética de Gilles Deleuze.
} 
den a un sistema de categorías cristalizado por la tradición moderna: la obra, el autor, las influencias; sistema que rige en las asignaciones de valor y sentido y regula los umbrales de visibilidad y el que, en última instancia, le permite a la Historia del Arte sostener la tesis de existencia de sus objetos.

En términos de Gilles Deleuze, podemos afirmar que la representación histórica de la obra de arte desarma una máquina para confirmar las funciones (de límite, coherencia y continuidad) de un nuevo conjunto cuyo modelo es el del corpus orgánico. A través de los libros de historia del arte, artefactos a la vez escritos y visuales, en los que este saber se asienta, queda definido el espacio de su inscripción.

Por sus aspectos semánticos y pragmáticos, los libros de historia del arte, presentan principios de demarcación nítidos, marcan un adentro claramente deslindando de un afuera, y construyen un espacio de sentido conclusivo. En oposición, las imágenes habitan en una intemperie del Sentido por la que circulan flujos a-significantes: un espacio de conexiones múltiples y no codificadas. Lo que se trata de indagar es entonces el modo en el que el dispositivo libro participa en la operación historiográfica de constitución de la obra de arte.

Las prácticas contemporáneas que comentaremos más adelante discuten esta clausura de los relatos históricos sobre el arte que el estatuto del libro enfatiza. Esta discusión es una forma de contender con los modos y con los atributos de la clausura en la definición moderna de la obra de arte (unicidad, límites claramente establecidos, separación con respecto al continuum de la vida) pero sobre todo, con la Historia del Arte como su interpretante privilegiado o, para usar una noción cara a J. Derrida $(1997,2012)$ como el arconte de sus archivos. Determinadas prácticas artísticas, informan sobre un estado de las creencias acerca del poder de la Historia del Arte para representar el pasado. Estas intervenciones pueden entenderse como operaciones de lectura que ponen en crisis su verosimilitud y eficacia referencial. En particular, las intervenciones contemporáneas que consideramos toman como material de su intervención el libro de historia del arte, esto es, el objeto impreso en el que se asienta y se produce el discurso disciplinar.

\section{El libro de Historia del Arte}

Desde la obra de Michel Foucault, sabemos que los objetos no preexisten a los dispositivos sino que se configuran en las líneas de visibilidad que permite su arquitectura. En este sentido, los libros de historia del arte hacen aparecer sus propios objetos a través de un sistema de delimitación de lo visible y lo decible, por medio de procedimientos que aíslan un espacio de inscripción de las imágenes, técnicas específicas de distribución y de consignación. El registro produce a sus objetos como a través de una pantalla que obtura y tamiza sus zonas de visibilidad y que delinea los contornos que pasarán a ser tomados por los propios del objeto.

La imagen del libro como fuente de sentido ha sido estudiada por Jacques Derrida, en el capítulo que abre De la gramatología. En este apartado, la noción de libro es opuesta a la del texto y a la de escritura; se presenta como imagen de un habla que pretende ser plena (2012, p. 14). A través de la historia de sus metáforas, señala Derrida, puede advertirse que su idea es (...) la de una totalidad, finita o infinita, del significante; esta totalidad del significante no puede ser lo que es, una totalidad, salvo si una totalidad del significado constituida le preexiste; vigila su inscripción y sus signos, y es independiente de ella en su idealidad. (2012, p. 25)

La imagen del libro es entonces la de una totalidad que se imagina como preexistente desde un origen del libro que la guarda entre sus tapas. La metáfora de la Historia como un libro cuyas páginas van quedando escritas por los mismos hechos que son dignos de memoria, ${ }^{5}$ se mueve en el mismo horizonte que no puede reducirse a una simple metonimia en la que el efecto se dice por su causa. El pasado se imagina como ya escribiendo el libro que en el futuro lo relatará.

Desde la Historia del Arte en la Antigüedad de Winckelmann (1764), con la que cristaliza el concepto moderno de Historia del Arte y, más aún, desde el Manual de Historia del Arte de Franz

\footnotetext{
5 Este tópico fue señalado por Ernst Curtius, en su recuento de topoi de la cultura occidental, en el capítulo "El libro como símbolo". Derrida menciona este texto en el primer capítulo de De la gramatología pero no puntualmente el topos del libro de la historia.
} 
Kugler (1842), con el que se inaugura la Historia del Arte Universal como género editorial, la eficacia del discurso que pretende comprender una totalidad es indisociable del simbolismo del libro y de sus posibilidades materiales como tecnología de archivación. ${ }^{6}$ Se trata de inscribir en él una obra de arte y de mostrarla como perteneciendo a una totalidad viviente, orgánica, la del arte como proceso histórico universal. Pero las obras en las que este proceso se manifiesta solo componen una unidad entre sí en la totalidad imaginaria del libro en el que se fabrica el espacio de su contigüidad. Fuera del libro que las colecciona y que las escribe como artísticas, las imágenes están desperdigadas en el espacio social y asignadas a distintas funciones; en este fuera-del-libro la Historia no es el espacio de una totalidad sino el "espacio de una dispersión" (Foucault, 1990). De este modo, el libro de Historia del Arte está vinculado también a la noción de colección a la que toda una línea de pensamiento asocia con la voluntad de reponer una totalidad y de asegurar su clausura. ${ }^{7}$

Las técnicas de reproducción mecánica de la imagen artística (el grabado en acero, la litografía y luego el fotograbado) jugaron un rol central en la consolidación de las tecnologías de la historia del arte como saber. La imagen grabada o fotográfica del objeto que se reconoce como artístico permite su inserción en marcos de referencia diferentes a aquellos en los que participó inicialmente. De este modo, el objeto artístico pierde la conexión que lo ligaba a su procedencia y se hace iterable. Es justamente esta pérdida de una conexión necesaria con la primera localización la que permite que la escritura, que es siempre lenguaje en ausencia, pueda tener lugar; es esta fractura o desnivel entre producción y reconocimiento la que permite

6 Johann Joachim Winckelmann, aseguraba que no había quedado obra del arte de los griegos que no haya sido vista por sus propios ojos antes de publicar su Historia. Respecto a la noción de Historia del arte universal, con frecuencia se le achaca una procedencia hegeliana. En términos históricos, esta atribución debería ser relativizada ya que, como demostró $\mathrm{E}$. Gombrich, la noción de historia del arte en la Estética de Hegel se deriva directamente de la lectura que el filósofo realizó de la obra de Winckelmann

$7 \quad$ A este respecto cfr. Baudrillard (1967). Muchas lecturas se hicieron de la tesis de Baudrillard sobre la colección, en particular sobre su carácter de sistema semiótico cerrado cfr. Stewart, S. (2012). que una historia del arte se escriba. No hay escritura de la historia sin la ausencia de su objeto: la historiografía es la constante producción de signos sobre eventos y entidades que se encuentran en otra parte. Es justamente como compensación de esa ausencia que un efecto de presencia - la vivacidad o enárgeia-cubre grandes bloques de su discurso (de Certeau, 2004).

Jacques Rancière (2012), ha señalado que el régimen de inscripción de los objetos en la Historia del Arte no depende de su poiesis - es decir, de sus reglas de producción- sino de su aisthesis, de la manera en que son restituidos a un determinado ámbito sensible. No son los principios de ejecución técnica los que signan a un objeto como artístico, sino que estos objetos se adscriben al régimen del arte como resultado de determinadas reglas que operan en situación de reconocimiento, para decirlo con los términos del análisis del discurso veroniano. (Verón, 1997)

La operación de coleccionar, escoger objetos de diferentes procedencias para reponer su pertenencia a una totalidad es la gramática con la que se constituye este espacio de reconocimiento de lo artístico. En la colección, en la formación del corpus, sucede como en la lógica del libro. Se trata de una totalidad que se imagina como anterior, pero que en rigor está siempre por ser constituida; no es un origen dado sino por venir, el movimiento hacia una totalidad que por definición es imaginaria.

En el libro de Historia del Arte, la obra reproducida aparece como suplemento de un origen ausente. Es la copia de algo original que existiría en otra parte, pero eso otro, solo se inscribe como artístico a través de la copia con la que la imagen ingresa al relato histórico.

La filosofía deleuziana, nos aporta también herramientas para pensar la génesis de un libro de Historia del Arte. Una Historia del Arte se hace con líneas de molarización con las cuales lo múltiple queda subordinado a lo Uno (el Artista, la Evolución, el Estilo de época). Es el llamado a un General que recusa lo singular para salvar los contornos de las grandes entidades ideales que organizan toda Historia del Arte General. El libro de Historia del Arte produce la universalidad del arte que lo sustenta. Como recuerda Deleuze en uno 

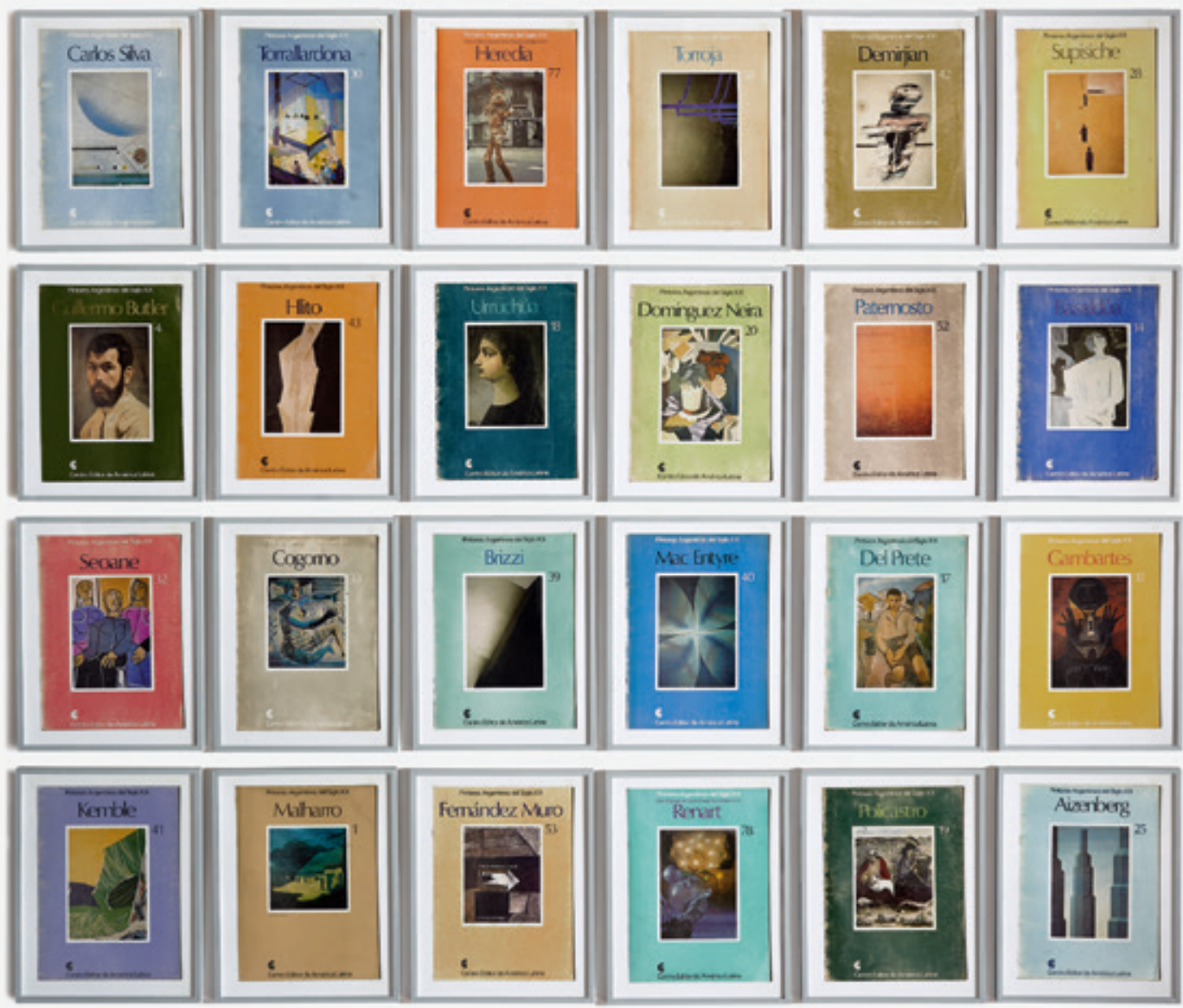

Guillermo Faivovich, (2011) Pinturas y fotografías. 
de sus textos sobre el concepto de dispositivo, no existen los universales sino procesos de unificación y de totalización que son inmanentes a cada dispositivo (1990, p. 58).

La Historia del Arte codifica flujos que son espacios-señales y en los que procede por cortes, estableciendo segmentos donde solo existen continuidades. Parcializa en el sentido en que transforma las zonas (que responden a la vida) en partes (que responden a su representación orgánica). Estas parcelas son como los capítulos de libros en los que se registran y distribuyen las señales bajo el imperio de lo Mismo. Así, la Historia del Arte es una serie de inscripciones orgánicas, se hace un organismo con una dispersión de ocurrencias.

El libro-raíz, como lo conceptualizó Deleuze se ajusta a todas las características del libro tradicional de Historia del Arte: representación orgánica de una bella interioridad, atribuida a un sujeto, con una relación de tipo representativa con el mundo. "Lo Uno que deviene dos" (2004, p. 11) aparece en todos los panoramas y esquemas del arte universal en los que los árboles genealógicos y cuadros de generaciones organizan el pasado artístico en un universo filiativo y binario. Por fin, la estructura de los capítulos, ya sea por generaciones, escuelas o autores, presenta los sistemas de partición de la representación clásica; no son criterios inmanentes a las imágenes artísticas los que se toman para ordenar sus materiales sino las divisiones típicas del libro como realidad espiritual.

\section{Mostrar las inscripciones, desorganizar el libro}

En los apartados previos caracterizamos la operación en la que la Historia del Arte hace con las obras un corpus orgánico: un organismo construido por metáforas biológicas (nacimiento, evolución, florecimiento, muerte) pero también como corpus legal, un conjunto cuya gramática de producción pretende tener fuerza de necesidad y de ley (en este sentido, cada ocurrencia del término corpus reinscribe el paradigma del Corpus luris). El espacio de ese corpus es el libro. Artistas como los argentinos Santiago Villanueva, Guillermo Faivovich y Martín Legón toman al libro pero en un régimen distinto al de la representación libresca, no como objeto sino como ob-juego (objeu). No se trata de asumir lo que en él se declara ni de impugnarlo, sino de mostrar lo que tiene de cuerpo sin órganos, de abrirlo a su exterior y a lo que no está gobernado por el Sentido. Estos artistas se ponen a trabajar con su materia, como en una mesa de operaciones. ${ }^{8}$

La exposición de Guillermo Faivovich, Pinturas y fotografías, se instaló en dos secciones, una de ellas en la galería de arte Mite y la otra en la librería especializada Purr; ubicadas ambas a pocos metros de distancia en la galería porteña Patio del Liceo. En la librería, Faivovich distribuyó sobre la pared 24 fotografías que reproducían las cubiertas de los fascículos de la colección "Pintores argentinos del siglo XX", colección editada a comienzos de la década de 1980 por el Centro Editor de América Latina. Vistas a cierta distancia, las fotografías parecían ser los fascículos mismos o sus tapas, ya que conservaban la escala y el formato de la publicación. La distribución formaba una grilla de seis fotografías a lo ancho por cuatro a lo alto.

En su cubierta, los fascículos del Centro Editor muestran la obra de arte empequeñecida, miniaturizada, rodeada por un marco blanco perimetral y amplios bordes de colores plenos que ocupan la mayor parte de la cubierta. ${ }^{9}$ Este parergon se hace aún más visible por el modo en el que Faivovich presenta los fascículos, estructurados en una grilla, lo que remarca la repetición del marco. En tanto escritura, la Historia del Arte es producción de una miniatura, una técnica de abreviación que "reduce las dimensiones de la presencia dentro de su signo" (Derrida, 1971, p. 354).

El componente de copia aparece remarcado por un procedimiento de puesta en abismo. Se trata de fotografías que reproducen la cubierta de una obra (cada fascículo del Centro Editor) en la cual lo

\footnotetext{
8 Las nociones de ob-juego y de mesa de operaciones están tomadas del libro de Raúl Antelo, Archifilologías latinoamericanas. Lecturas tras el agotamiento, y remiten respectivamente a la idea de ob-jeu, juego de palabras del filológo de inspiración derrideana Werner Hamacher, y a las reflexiones sobre el cuadro como archivo y mesa de trabajo en Georges Didi-Huberman. En ambos casos, remiten a una escena de intervención con materiales del pasado cuya construcción pone en tensión la relación clásica sujeto analista - objeto de análisis.

9 La medida de los fascículos es en todos los casos de 33,5 x $24 \mathrm{~cm}$; la diagramación de la cubierta también es invariable, las manchas que corresponden a los cuadros miden $19 \times 13 \mathrm{~cm}$.
} 


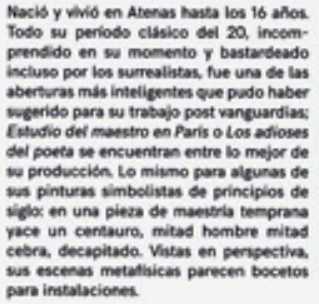

distintivo es la fotografía que reproduce una obra (del pintor al que está dedicada la monografía). Lo que esta mise en abyme pone en foco es la imagen de una obra que solo existe dentro de otra obra, de una obra que existe por obra del marco historiográfico. Esta lectura es incluso válida en términos históricos por la selección de los fascículos tenidos en cuenta por Faivovich (Domínguez Neira, Gambartes, Supisiche, Butler, Urruchúa), correspondientes a pintores que fueron canonizados en distintos momentos del siglo XX y que, con excepción de los especialistas, cayeron posteriormente en el olvido. Además de su característica regularidad, las portadas del Centro Editor se distinguen por la frugalidad de los elementos paratextuales. Encontramos, solamente, el número que el fascículo tiene en la colección y el apellido del artista. En el espacio gráfico neutro de la cubierta estas dos marcas aparecen realzadas en lo que remiten a operaciones de la escritura histórica. La numeración reenvía a la práctica de serializar las biografías, de constituir un corpus. Las coordenadas las proporciona la correlación numérica pero también la partición en series que se anexan al cuerpo principal. Junto a los "Pintores Argentinos del Siglo XX" que daban nombre a la colección estaban los "Escultores argentinos del Siglo XX" y los "Grabadores argentinos del siglo XX" a título de "series complementarias". En la estructura editorial de la colección se (re)producía un pequeño sistema de las artes, en el que el centro del relato lo ocupaba la modernidad pictórica.

El nombre, por su parte, remite a la producción de la unidad de autor y a la invención de la firma del artista a través de ese poder del albacea que es el de la contrafirma. Como albacea de la memoria artística, arconte de su archivo, la Historia del arte certifica la legalidad y la extensión de las firmas, el ámbito legítimo que corresponde a cada artista. Lo que Faivovich fotografía y encuadra, y repone 


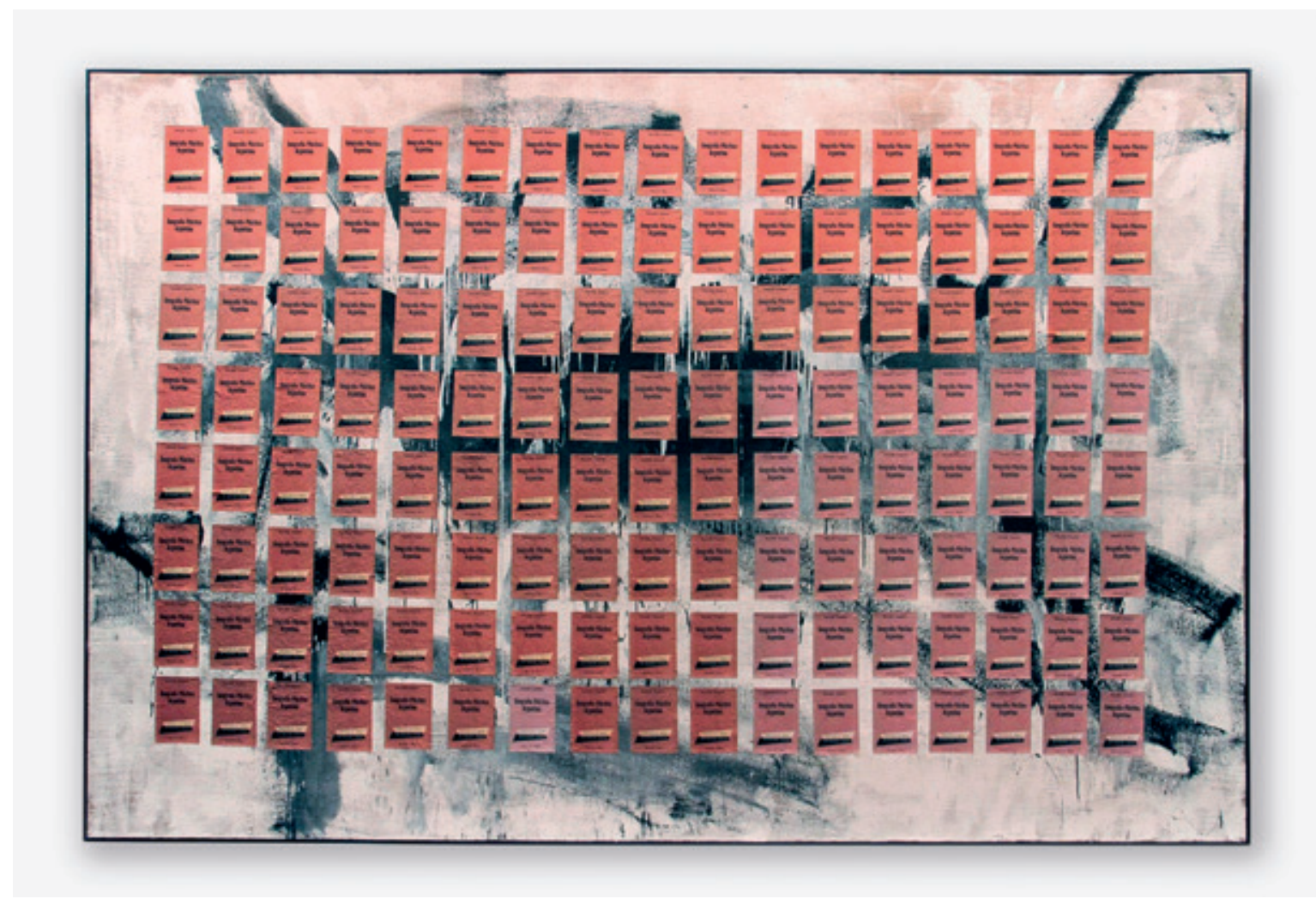

Santiago Villanueva. Sin título. (Santiago Villanueva, 2013) Museo Franklin Rawson.

a su vez en otro sistema de encuadre —la grilla del montaje - es el sistema mismo de encuadre en el que las autorías son producidas. En este sistema se inventa un cuerpo de obras y también su clausura: el corpus de cada artista se pone entre tapas. El nombre del artista está en una posición particular de exterioridad y contigüidad respecto a ese libro: sobre la tapa, por fuera su contenido pero pegado a él, se inscribe respecto al mismo en un plano de trascendencia.

Al igual que Faivovich, Martín Legón, tomó como mesa de operaciones para su trabajo el espacio editorial de una colección. "Pintores argentinos del siglo XX" se anunciaba como "la más importante colección de arte argentino". En dos proyectos, Martín Legón, trabajó con la "Colección Globus", en sus palabras, una síntesis de la pintura moderna europea en 48 tomos (Legón, 2016, p. 5). En Soundtrack para los 48 tomos de la colección Globus (2011) Legón grabó música para cada uno de los volúmenes de esta colección, editada en
Madrid entre 1993 y 1995. Al igual que la obra de Faivovich, la resolución expográfica del proyecto fue el montaje en forma de grilla. Cada volumen de la colección aparece dispuesto en forma horizontal y sobre cada uno, se encuentra un cassette con la grabación de su contenido, dispuesto en forma vertical. La elección del cassette como forma de almacenamiento remite a las formas de gestión de la información disponibles en la época en que esta pinacoteca fue editada. En este caso la colección es puesta en escena en forma íntegra. Con el cassette colocado sobre cada libro se replica el efecto del libro como continente que guarda un contenido de información.

En el 2016, Legón retoma el proyecto con la publicación de Apuntes a la Colección Globus, un libro de 100 páginas editado por la galería Big Sur. El libro comienza con un prólogo donde señala el efecto de absurdo que la colección de libros sobre pintores le ofrece actualmente. En las páginas subsiguientes, reproduce la portada de 
cada uno de los tomos y en la página opuesta a cada portada, un comentario sobre el mismo derivado de su experiencia de lectura. La operación de lectura que lleva adelante Legón en este caso reduce la obra al texto; si la primera tiene puntos de acceso privilegiados, el segundo es un puro movimiento en el que se puede ingresar, como en el rizoma, por cualquier entrada. La solidez monumental del canon, un canon del que se descubre su materialidad específica -la de una práctica editorial- queda pulverizada con la lectura de Legón. Las recensiones que el artista anota sobre cada libro se agotan en la mención de aspectos secundarios, acercamientos afectivos y un registro por momentos coloquial que evoca con eficacia el universo de la experiencia concreta de una lectura. El universal de la colección es reprogramado por la lectura singular y contingente con la que cual el canon se desarma y vuelve a armarse en un nuevo libro, pero esta vez mostrado en cuanto tal.

Al igual que en Faivovich, el efecto de repetición aparece con la multiplicación en serie de las portadas. Estas se ven focalizadas, en una nueva coincidencia, en su valor de copia (enfatizada a través de una digitalización imperfecta, con las marcas del fotocopiado). Aparte de la firma del artista y del sello de Globus, las portadas presentan otro principio de demarcación: los años de nacimiento y de defunción del artista. Todos estos aspectos destacan de la operación historiográfica la construcción de su objeto a través de parcelaciones. En este caso, también está la idea de leer la colección desde un principio hasta el final: un efecto directo de la obra, de los límites del libro como artefacto material. Esta idea está llevada a la práctica pero como práctica que se muestra como artística y contemporánea, entendiendo con lo primero una fabricación artificial $y$, por lo segundo, lo intempestivo e inactual.

Los proyectos del artista Santiago Villanueva están dedicados a "revisitar la historia del arte argentino" a partir de las exclusiones de una "historiografía canónica" (Villanueva, 2013). En este volver a visitar, las cubiertas de los libros en los que esa historia del arte se escribió, aparecen con frecuencia. En el 2012, en el marco de las I Jornadas de Arte Contemporáneo Latinoamericano, llevó a cabo una exhibición que consistió en fotocopias en hojas A4 de tapas de libros de Historia del Arte argentino. En 2013, realizó una exposición en la
Fundación Cisneros Fontanals de Miami, con el título "Geografía Plástica Argentina", el mismo título que llevaba un libro programático de historia de la pintura argentina escrito en 1958 por Romualdo Brughetti. Una vez más, los programas de la Historia del Arte se exponen como proyectos fallidos: en el último caso el programa imposible de Brughetti, correspondía a delimitar una teoría de la pintura argentina a través de la demarcación de la luz nacional que diferenciaba la producción plástica del país de la de otras naciones. La exposición se materializó en una serie de fotografías de bastidores hechos con tela arpillera. Esas telas (que evocaban la materialidad de los bastidores de muchas pinturas argentinas de mediados de siglo) presentaban adheridas a su superficie reproducciones de obras recortadas del libro Geografía Plástica Argentina, colocadas en distintos sentidos, con una distribución centrífuga sin patrones regulares. El discurso de la Historia del Arte - es este caso, el programa para una historia del arte nacional- aparecía como un proyecto fallido. Del monumento al Estado que pretendía ser la Geografía de Brughetti se pasa a estados de las imágenes impresas que en los lienzos aparecen plegadas por el pegamento, cruzadas por hilos, manchadas en zonas con pintura al óleo. En primer lugar, estas imágenes son una reproducción de un bastidor atravesado por reproducciones (por tanto reproducción de reproducciones). Más allá de esa certeza aparece una ambigüedad entre dos imágenes: por un lado los indicios de una pintura que está en proceso de construcción, con trazos de pintura y fragmentos de impresos que remiten a la práctica del collage en las vanguardias históricas; por otro, la distribución azarosa de reproducciones y libros en la mesa de un crítico, desde luego, el escritorio de Romualdo Brughetti. En las imágenes que escribe bajo el nombre de un libro, Villanueva le devuelve a todos los materiales de ese libro su materialidad (de las telas, de las técnicas de reproducción fotográfica, del pegamento visible con el que las reproducciones se adhieren a la tela). Pone de relieve, en fin, la materialidad de la operación historiográfica y escenifica el lugar donde se escribe la obra (a la vez donde se confecciona la imagen y donde se le asigna un estatuto en el sistema del arte). Los elementos elegidos por Villanueva y su disposición no exponen el corpus de Brughetti sino que desfiguran la representación orgánica de la historia: hacen con el corpus ese libro un cuerpo sin órganos. 
Las imágenes tienen una disposición semejante a otra intervención de Villanueva: el Museo del Fondo del Paraná, donde la idea de Historia es reemplazada por una temporalidad marcada por el devenir y el caos. Se trató de un proyecto en el que Villanueva compró pinturas de artistas argentinos de principios de siglo XX agrupados por la historiografía como artistas del Litoral, y las arrojó al Río Paraná para registrar luego las alteraciones que las obras sufrían: sedimentaciones de arena sobre la pintura, desprendimientos de capa pictórica, despegue de la tela respecto a los marcos. Las obras fueron recuperadas del agua y exhibidas en ese estado. Así mismo, fueron fotografiadas desde una navegación con un punto de vista picado, mientras flotaban sobre el Paraná. El resultado visual es muy semejante al de las reproducciones de cuadros y de tapas de libros que flotan sobre los bastidores en "Geografía Plástica Argentina" y otros proyectos del artista. Sobre el fondo de contraste de la historiografía tradicional, el lanzamiento de las obras al río reintroducía en forma literal el espacio de inscripción que la historiografía había asignado a esas pinturas (catalogados como artistas del Paraná o del Litoral). Pero los términos poéticos de esta operación exponían además las pinturas a una intemperie del sentido, a lo impersonal y el devenir.

Tanto los proyectos de Faivovich, como los de Villanueva, hacen un uso poético de la reproducción fotográfica de obras. Esta es reconocida como suplemento: no solo se añade a la obra de arte sino que también la suple y la inventa en esa suplencia. La reproducción no aparece propiamente como divulgación porque ésta última supone la existencia un origen que sería vulgarizado. En cambio, la materia de estos proyectos es la obra de arte entendida como un momento de inscripción de la imagen en la escritura y en la copia. Lo que estos artistas hacen visible es la opacidad del discurso histórico artístico que encuentra en la representación libresca su principal operación productiva.

\section{La (imposible) conclusión}

Pensar los espacios editoriales de un saber, como la Historia del Arte, es pensar sus tecnologías y lo que ellas producen sobre la imagen, imagen que se convierte en obra de arte y en pieza de un corpus con su ingreso a la historiografía. Esta inscripción es denegada por el discurso: la obra es siempre representada como anterioridad del sentido que se entrega ya pleno al libro, espacio donde solamente se duplica como un reflejo.

Los proyectos artísticos comentados hacen visibles las líneas del dispositivo: líneas de visibilidad y de enunciabilidad. La historia del arte, sus espacios de enunciación y sus metáforas y -sobre todo-sus asientos materiales son expuestos como textualidad sin los marcadores idealistas de la obra, el artista, el corpus iuris de la historia.

El síntoma de la crisis del libro no es su extinción sino su proliferación, la multiplicación de las prácticas que lo conservan y lo señalan y que lo articulan en otros universos. Por otra parte, esta crisis no es la de un objeto sino la de un modo de lectura cuya idea lleva implicada la de totalidad, la relación orgánica entre las partes y el efecto de clausura. Los desarrollos del trabajo intentaron conceptualizar la centralidad del libro para la disciplina de la Historia del Arte y su estatuto como espacio de escritura y de archivación de lo artístico. No obstante, la delimitación de esta cuestión problemática y el reconocimiento de su importancia para la Estética continúan las señales que emiten las más recientes prácticas artísticas. Antes que la investigación académica, fueron estas prácticas las que pusieron en foco los discursos de la Historia del Arte y sus tecnologías impresas haciendo ver su rol en la delimitación de lo artístico. En este sentido la imagen de pensamiento que orientó la exposición teórica de este trabajo fue la imagen que ofrecen las mismas prácticas que comentamos. Esta imagen es la de la Historia del Arte como un dispositivo y un espacio de inscripción que solo se hace pensable como tal en el momento de su crisis.

\section{Referencias}

Agamben, G. (2011). "¿Qué es lo contemporáneo?",

En Desnudez. Buenos Aires: Adriana Hidalgo.

Baeza, F. (2010). "El arte contemporáneo y la documentación de las prácticas estéticas cotidianas", en De signos y sentidos $N^{\circ} 1$.

Barthes, R. (1971). “De la obra al texto", en Revue d'Esthétique N³.

(1987). "La muerte del autor", en El susurro del lenguaje.

Buenos Aires: Paidós.

Baudrillard, J. (1967). Le système des objets. París: Gallimard. 
Beaulieu, A. (2012). Cuerpo y acontecimiento. La estética de Gilles Deleuze. Buenos Aires: Letra viva.

De Certeau, M. (2004). La escritura de la historia. México: ITESO.

Debray, R. (1994). Vida y muerte de la imagen. Historia de la mirada en Occidente. Barcelona: Paidós.

Deleuze, G. (1990). ¿Qué es un dispositivo?, en A.A.V.V. Michel Foucault filósofo. Barcelona: Gedisa.

PMCid:PMC54762

(1978). ¿Qué es un dispositivo?, en Kafka.

Por una literatura menor. México: Era.

Deleuze, G., y Guattari, F. (2004). El Anti-Edipo. Capitalismo y esquizofrenia. Barcelona: Paidós.

(2004). Mil mesetas. Capitalismo y esquizofrenia. Valencia: Pre-textos

Derrida, J. (2010). "Parergon", en La verdad en pintura. Buenos Aires: Paidós.

(1997). Mal de archivo. Una impresión freudiana. Madrid: Trotta.

(2012). De la gramatología. México: Siglo XXI.

Didi-Huberman, G. (2010). Ante la imagen. Pregunta formulada a los fines de una historia del arte. Murcia: CENDEAC.

Didi-Huberman, G. (2009). "El arte muere, el arte renace: la historia vuelve a comenzar (de Vasari a Winckelmann)", en La imagen superviviente. Historia del arte y tiempo de los fantasmas según Aby Warburg. Madrid: Abada.

Foucault, M. (1990). La arqueología del saber. Madrid: Siglo XXI. PMCid:PMC171908

Guasch, A. M. (2011). Arte y archivo (1920 - 2010). Madrid: Akal. Legón, M. (2016). Apuntes a la colección Globus. Buenos Aires: Big Sur.

Nietzsche, F. (1999). Sobre la utilidad y el periuicio de la historia para la vida. Il intempestiva. Madrid: Biblioteca Nueva.

Rancière, J. (2005). Sobre políticas estéticas. Barcelona: Servei de Publicacions de la Universitat Autónoma de Barcelona.

(2012). Asithesis. Escenas del régimen estético

del arte. Buenos Aires: Manantial.
Stewart, S. (2013). El ansia. Narrativas de la miniatura, lo gigantesco, el souvenir y la colección. Rosario: Beatriz Viterbo / UNR. https://doi.org/10.1002/9780470015902.a0022493

Van Alphen, E. (2006). "¿Qué historia; la historia de quien; historia con qué propósito? Nociones de historia en historia del arte y en estudios de cultura visual", en Estudios visuales, $N^{\circ} 3$. Recuperado de http://estudiosvisuales.net/revista/pdf/num3/ alphen.pdf

Vattimo, G. (1987). “Muerte o crepúsculo del arte”, en El fin de la modernidad. Barcelona: Gedisa.

Verón, E. (1997). La semiosis social. Barcelona: Gedisa. PMCid:PMC23778

Villanueva, S. (2013). "Entrevista al artista". Disponible en: https://www.youtube.com/watch?v=QbtLXOd33fE\&t=11s

Zourabichvili, F. (2007). El vocabulario de Deleuze.

Buenos Aires: Atuel. PMid:17697398 